\title{
Characterisation of Residual Soils of Volcanic Origin and Its Possible Implications for Soil Stabilisation
}

\author{
Rajeshwar Goodary ${ }^{1}$, Gisele Lecomte ${ }^{2,}$ Miraniaina Adriamalala ${ }^{3}$ \\ ${ }^{1}$ Université des Mascareignes \\ Avenue de la Concorde, Roches Brunes, Rose Hill, Mauritius \\ rgoodary@udm.ac.mu \\ ${ }^{2}$ Université de Limoges SPCTS Research Laboratory \\ 12 Rue Atlantis, 87068 Limoges Cedex \\ France \\ Gisele.lecomte@unilim.fr \\ ${ }^{3}$ Institut Supérieur de Technologie d'Antananarivo \\ Antananarivo, Madagascar \\ miraniaina2@yahoo.fr
}

\section{Extended Abstract}

Geotechnical behaviour of volcanic residual soils has always been a topic of discussion, mainly due to the fact that their engineering properties, to a large extent, depend on the genetics of the parent materials. Numerous 'misbehaviour' of volcanic residual soils have been reported and the main component causing discord is the presence of native expansive clay, the genetics and characteristics of which require an individual attention as they vary from one region to another [1]. Recent investigations have shown that expansive soils of volcanic origin have positively responded to common stabilising agents likewise, lime, cement and fly ash but their application turn out to be very expensive in practice [2][3].

This research ultimately aims at studying the behaviour of a particular expansive clay (DMC) when the latter is partially replaced by a non-expansive soil of volcanic origin (VK). Both materials are end products of volcanic basalt weathering process [4]. To be able to predict and interpret the behaviour of such mixtures, a rigorous characterisation of both materials is necessary.

The present paper focuses on the characterisation of Dark Magnesium Clay (DMC) - an expansive volcanic residual soil and another commonly occurring non-expansive volcanic soil (VK) occurring in the island of Mauritius with an aim to stabilise the DMC with varying contents of VK. DMC, belonging to the family of the Magenta group of soils, is sampled from the south western area of the country and VK, collected from the north western zone, belongs to the group of low humic latosols of the Richelieu family [4][5]. Facilities of the SPCTS research laboratory (University of Limoges, France) namely X ray diffractometer, SEM electron microscope, BET for specific surface determination, thermogravimetric and $\mathrm{XRF}$ analysers among others, have been used for a complete characterisation of the materials.

Visually the DMC is plastic to very plastic light grey silty clay whereas VK is slightly to moderately plastic reddish brown silty clay. X-ray diffractograms reveal the main component in DMC to be montmorillonite clay fractions which obviously explains its expansive behaviour and VK contains essentially kaolinite, goethite and hematite which are coherent with SEM images showing well defined layers of montmorillonite in the DMC. Furthermore, images show some scattered montmorillonite clay particles hiding among the main population of kaolinite in VK, which explains the insignificant swelling of soils of VK family. Specific surface area for both samples are found in the range of $79-83.4 \mathrm{~m}^{2} / \mathrm{g}$, indicative of a possible favourable interaction between the clays, necessary for stabilisation, provided they are reactive. Particle size distribution curves obtained by using laser granulometry analyser shows unpredictable results and as such, VK is populated by two distinct populations residing in the ranges $0-0.8 \mu \mathrm{m}$ and $0.8-30 \mu \mathrm{m}$, compared to a single population for DMC, that is $0-100 \mu \mathrm{m}$. On the other hand Loss on Ignition (LOI) for both clays are found to be in the range $15-16.5 \%$ which are comparable to naturally occurring clays.

The above characteristics indicate that volcanic kaolinite (VK) possesses the complementary properties to share with expansive DMC and partial replacement of DMC by VK may yield an acceptable material for civil engineering works. 
Keywords: Volcanic Residual Soil, Expansive Soil, Dark Magnesium Clay, Soil Stabilisation, Montmorillonite, Kaolinite.

\section{References}

[1] D. E. Jones and W. G. Holtz, "Expansive Soils - the hidden disaster," Civil Engineering, ASCE, vol. 43, no. 8, pp. 49-51, 1973.

[2] R. Goodary et al., "Investigation of the strength properties of cement stabilised soils of volcanic origin," Construction and Building Materials, vol. 28, pp. 592-598, 2012.

[3] R. Goodary et al., "Stabilisation of Volcanic Dark Magnesium Clay using lime," in Proceedings of the 2nd World Congress on Civil, Structural, and Environmental Engineering (CSEE'17), 2017. DOI: 10.11159/icgre17.192.

[4] V. Proag, "The geology and water resources of Mauritius," Mahatma Gandhi Institute; Mauritius, 1995.

[5] R, Goodary et al., "Effect of Fly Ash on Strength and Compressibility of Dark Magnesium Clay," in Proceedings 'Advances in Civil Engineering for Sustainable Development', Thailand, pp. 437-442, 2014. 